\title{
Increased circulating atrial natriuretic factor concentrations in patients with chronic heart failure after inhibition of neutral endopeptidase: effects on diastolic function
}

\author{
David B Northridge, Alan Jardine, Esther Henderson, Stephen G Dilly, Henry J Dargie
}

\begin{abstract}
Objective- \pm Candoxatrilat was used to raise atrial natriuretic factor (ANF) concentrations in patients with heart failure, and the effects on left ventricular systolic and diastolic function were studied to determine the contribution of peripheral and central mechanisms to the haemodynamic effects.
\end{abstract}

Design-This was a single blind, randomised comparison of \pm candoxatrilat and placebo in patients with mild heart failure. All patients received two intravenous doses of \pm candoxatrilat and two placebo doses on four consecutive days.

Setting-A teaching hospital department of cardiology.

Patients-Six men (mean age 52 years) with mild heart failure (New York Heart Association class II) due to ischaemic heart disease (four patients) or dilated cardiomyopathy (two patients) were included. Mean ejection fraction was $37 \cdot 5 \%$ and mean peak oxygen consumption was $20.4 \mathrm{ml} / \mathrm{min} / \mathrm{kg}$.

Main outcome measures-Plasma ANF concentrations, haemodynamic indices and left ventricular diastolic funstion measured by early to atrial filling rate (E:A ratio) with Doppler echocardiography were determined before and after \pm candoxatrilat and placebo.

Results- \pm Candoxatrilat caused a threefold rise of plasma ANF compared with placebo ( $p<0.005$ ), but there was no significant change in heart rate, blood pressure, or cardiac output. Mean right atrial pressure fell from 6.7 to 4.7 mm Hg (NS) and pulmonary artery wedge pressure fell from $9 \cdot 2$ to $6 \cdot 7$ mm Hg (p < 0.05). Doppler echocardiographic measurements of transmitral blood flow showed a significant fall in peak early left ventricular filling velocity from 39.5 to $34.2 \mathrm{~cm} / \mathrm{s}(p<0.05)$, along with a non-significant rise in peak atrial filling velocity from $39.7-41.6 \mathrm{~cm} / \mathrm{s}$ after \pm candoxatrilat. The E:A ratio, a Doppler index of left ventricular diastolic function, fell from a mean of 1.04 to 0.87 (p $<0.05)$.

Conclusions - \pm Candoxatrilat increased plasma ÁNF concentrations and reduced right atrial and pulmonary artery wedge pressures. No evidence of an improvement in left ventricular systolic or diastolic function was found, so the fall in preload was due to peripheral effects, either an increase in venous capacitance or a fall in circulating blood volume.

(Br Heart J 1992;68:387-91)

Atrial natriuretic factor (ANF) is a natriuretic and vasorelaxant peptide hormone secreted from the cardiac atria. ${ }^{1}$ Intravenous administration of ANF to patients with chronic heart failure produces a fall in right and left atrial pressure along with a diuresis and natriuresis. ${ }^{2-5}$ The cause of the fall in ventricular filling pressures is uncertain, but possibilities include an improvement in left ventricular systolic or diastolic function. Peripheral mechanisms may also be implicated, such as a reduction in plasma volume or an increase in venous capacitance.

A ubiquitous enzyme neutral endopeptidase (endopeptidase 24.11, EC 3.4.24.11, enkephalinase) degrades ANF in vivo. This enzyme is present in high concentration in the lungs and kidneys. ${ }^{67} \pm$ Candoxatrilat (UK 69 578, Pfizer Central Research) is a recently discovered specific inhibitor of this enzyme that has been shown to raise plasma ANF concentrations in animals and human volunteers. $^{89}$ It is a $50: 50$ racemic mixture of active and inactive isomers that is poorly absorbed from the gut and therefore has to be given intravenously. The active isomer of \pm candoxatrilat is now available as a prodrug with significant oral bioavailability-candoxatril.

We have used \pm candoxatrilat to raise plasma ANF concentrations in patients with chronic heart failure. The safety profile and renal effects of \pm candoxatrilat in these patients are reported separately. ${ }^{10}$ In this paper we describe the acute haemodynamic effects of raising plasma ANF concentrations by endopeptidase inhibition, in particular the effects on left ventricular diastolic function.

\section{Patients and methods}

\section{PATIENTS}

Six non-oedematous men with clinically mild (New York Heart Association (NYHA) class 2) chronic heart failure were included in this 
study. Their mean age (range) was 52 (44-61) years and the underlying diagnosis (confirmed by cardiac catheterisation), was ischaemic heart disease in four patients and dilated cardiomyopathy in two. All patients had objective evidence of both impaired left ventricular contractility and reduced exercise capacity. The mean left ventricular ejection fraction on first pass radionuclide ventriculography was $37 \cdot 5 \%$ ((range $28 \%-44 \%$ ) normal $>50 \%$ ). The mean exercise time (modified Bruce protocol) was 636 (416-888) seconds, with a peak oxygen consumption 20.4 ((16.0-24.9) normal $>25$ ) $\mathrm{ml} / \mathrm{min} / \mathrm{kg}$.

Patients were excluded if they had any of the following: present or previous hypertension (diastolic blood pressure $>100 \mathrm{~mm} \mathrm{Hg}$ ); hypotension (systolic blood pressure $<110 \mathrm{~mm} \mathrm{Hg}$ ); atrial fibrillation; primary valve disease; renal impairment (serum creatinine concentration $>200 \mathrm{mmol} / \mathrm{l}$ ); hepatic dysfunction (bilirubin concentration $>20$ ).

Approval was obtained from the local hospital ethical committee and all patients gave informed consent to the study.

\section{STUDY DESIGN}

Diuretic treatment was withdrawn two days before the study and all other medications were withdrawn for at least seven days. Patients were studied on four consecutive days in hospital and a standard diet containing $150 \mathrm{mmol}$ of sodium was maintained throughout. All studies began at 7.00 am with an oral fluid load of 200 $\mathrm{ml}$ of iced water, taken after voiding urine. Fluid balance was maintained during the subsequent 10 hours by voiding every hour and replacing urinary losses by drinking water.

\pm Candoxatrilat was diluted in $20 \mathrm{ml}$ of isotonic saline before intravenous infusion for 20 minutes. The neutral endopeptidase inhibitor or vehicle alone was given after the second hourly urine collection in a single blind fashion. Blood samples were taken at zero, one, two, four, and eight hours after dosing through an indwelling venous cannula and were analysed for packed cell volume, serum urea, and electrolytes. Plasma ANF was measured by radio immunoassay with an antibody raised locally after extraction in Sep-Pak cartridges, the normal range is $10-50 \mathrm{pg} / \mathrm{ml}^{11}$

On the evening of the second study day a balloon tipped catheter (7F Edwards Laboratories) was inserted through an antecubital vein and positioned in the right pulmonary artery under fluoroscopic control. Measurements of right atrial pressure, pulmonary artery pressure, pulmonary artery wedge pressure, and thermodilution cardiac output (mean of three injections of $10 \mathrm{ml}$ iced injectate, Edwards Laboratories cardiac output computer) were made on study days 3 and 4 at zero, one, two, four, and eight hours after dosing.

Echocardiographic studies were performed by a Hewlett Packard 77020 A system with a 2.5 $\mathrm{MHz}$ phased array transducer incorporating pulsed wave Doppler. The sample volume was placed in the left ventricle near the tips of the mitral valve in the four chamber view and was positioned to obtain the highest diastolic transmitral flow velocities. Doppler spectral profiles were recorded on video tape and analysed by integral software. The peak velocities during early and atrial diastolic filling were each averaged over 10 consecutive cardiac cycles. The E:A ratio, a Doppler index of left ventricular diastolic function, ${ }^{12}{ }^{13}$ was then calculated as peak early filling velocity:peak latefilling velocity.

\section{DOSING SCHEDULE}

This was the first study of \pm candoxatrilat in patients with chronic heart failure and therefore a wide range of doses, all of which had previously been well tolerated in normal human volunteers, was given. Each dose of \pm candoxatrilat or placebo was given on a separate day at around $9.00 \mathrm{am}$. For safety reasons, initial doses were small and larger doses were administered only if these were well tolerated. Patients were randomised in pairs with the first pair receiving active doses of $10 \mathrm{mg}$ then $20 \mathrm{mg}$ alternating with vehicle alone in random order. Similarly, the second pair of patients were given $50 \mathrm{mg}$ then $100 \mathrm{mg}$, and the final pair received $200 \mathrm{mg}$ and $400 \mathrm{mg}$. Because invasive haemodynamic measurements were only made on the final two study days, only the results from these days are shown-that is, doses of $20 \mathrm{mg}, 100 \mathrm{mg}$, and $400 \mathrm{mg}$.

\section{STATISTICAL ANALYSIS}

Data are therefore available for six active and six placebo infusions. They are presented as mean (SEM). The differences between active and placebo infusions were tested for statistical significance with repeated measures analysis of variance and, when indicated, Student's $t$ test for paired variables. A probability of $<0.05$ was taken as statistically significant. Baseline plasma ANF concentrations were positively skewed, and so the ANF data were transformed logarithmically before testing for significance.

\section{Results}

No drug related adverse effects occurred after \pm candoxatrilat. One patient with a primary

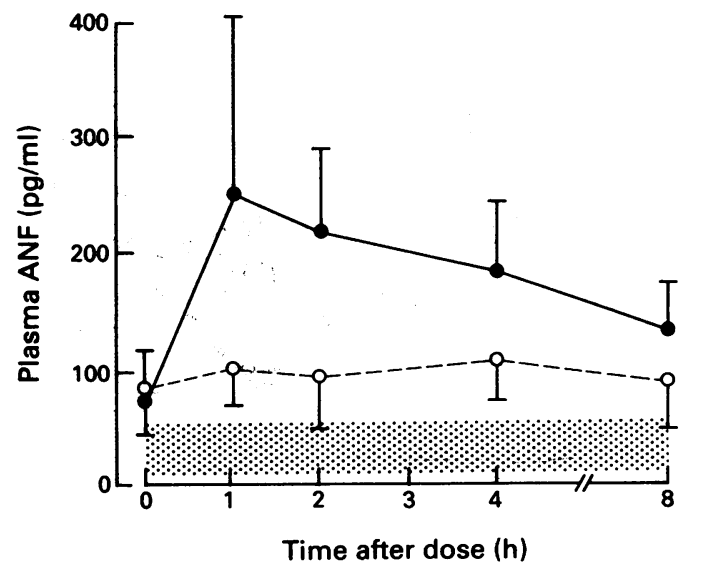

Figure 1 Plasma atrial natriuretic factor concentration (ANF) (mean (SEM)) after \pm candoxatrilat (solid lines, $n=6$ ) and vehicle alone (interrupted lines, $n=6)$. Normal range $(10-50 \mathrm{pg} / \mathrm{ml})$ is shown shaded 
Figure 2 Effects of \pm candoxatrilat on pulmonary artery wedge pressure (PAWA) and right atrial pressure $(R A P)$ (mean (SEM)) compared with placebo. Baseline is the mean of two predose measurements 30 minutes apart. Subsequent pressures are expressed as percentage change from baseline.
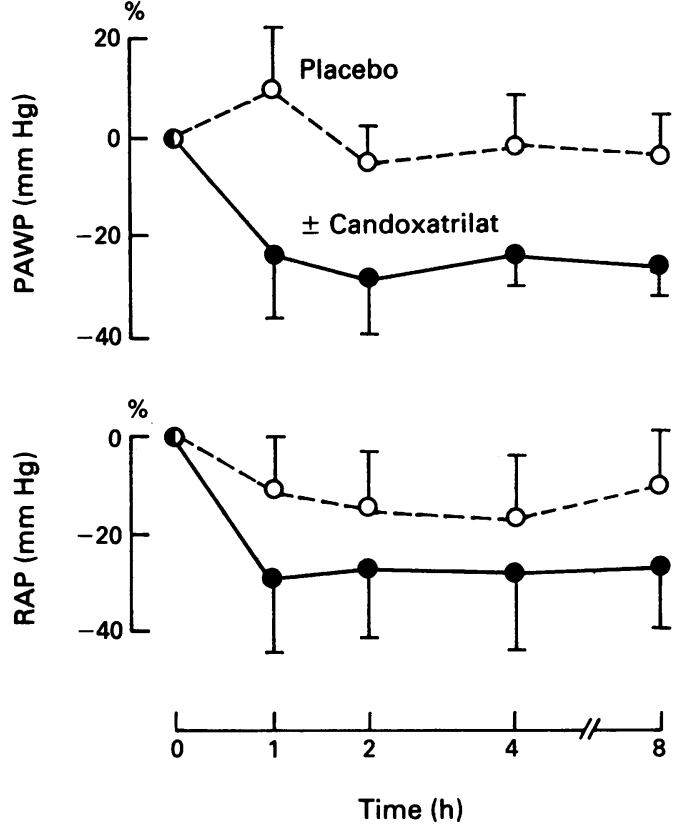

diagnosis of alcohol related dilated cardiomyopathy and normal coronary arteries developed chest pain two hours after infusion of placebo. This resolved spontaneously. Another patient developed skin inflammation over the course of the Swan-Ganz catheter in the upper arm, necessitating its removal before the final placebo dose. Therefore invasive haemodynamic data are available for five patients after the placebo and all six patients after \pm candoxatrilat

The mean (SEM) plasma ANF concentration was raised at baseline to 80.5 (23) $\mathrm{pg} / \mathrm{ml}$ (fig 1). After \pm candoxatrilat ANF concentrations rose to a peak of $226(97) \mathrm{pg} / \mathrm{ml}$ one hour after the infusion ( $p<0.005$ for difference from placebo). Plasma ANF had returned to baseline by eight hours. The peak ANF concentration did not appear to be dose related over the dose range under study. There was no change after the placebo (fig 1).

\section{HAEMODYNAMIC EFFECTS}

The principal acute haemodynamic effect after \pm candoxatrilat was a fall in cardiac filling pressures (fig 2). Right atrial pressure fell from
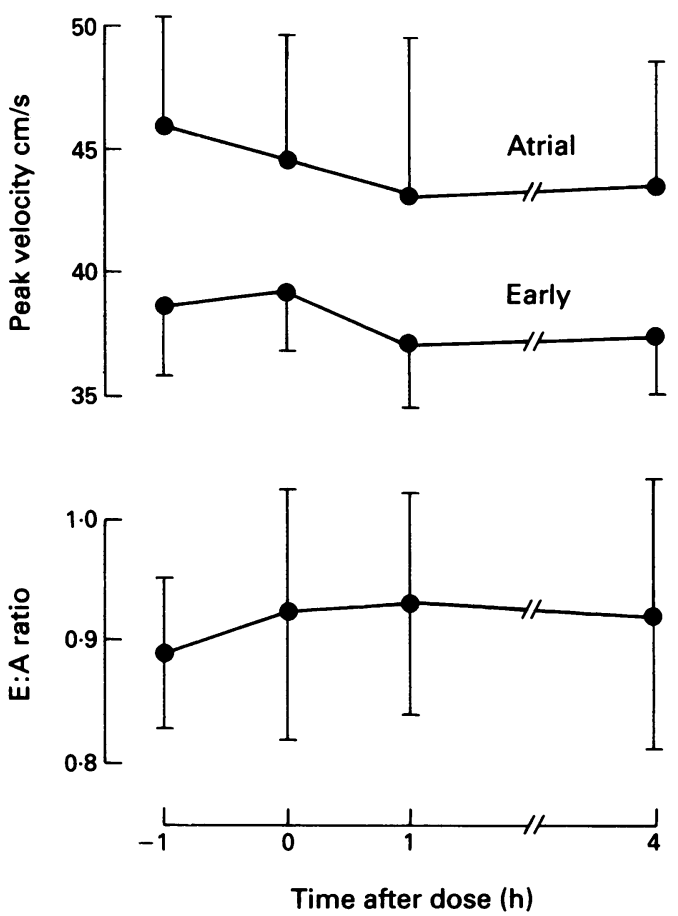

Figure 3 Doppler assessment of left ventricular diastolic function after placebo: mean (SEM) peak early and atrial filling velocities, and $E: A$ ratio.

$6 \cdot 7(2 \cdot 2)$ to $4 \cdot 7(2 \cdot 6) \mathrm{mm} \mathrm{Hg}$ (NS, $\mathrm{n}=6)$ and pulmonary artery wedge pressure fell from $9 \cdot 2$ $(1 \cdot 1)$ to $6.7(1.3) \mathrm{mm} \mathrm{Hg}(\mathrm{p}<0.05, \mathrm{n}=6)$. Filling pressures did not change significantly after administration of placebo $(n=5)$.

There were no significant changes in heart rate, systemic arterial blood pressure, cardiac output, or calculated peripheral vascular resistance after \pm candoxatrilat or placebo (table). Also, the packed cell volume was not affected by \pm candoxatrilat suggesting no change in the plasma volume.

LEFT VENTRICULAR DIASTOLIC FUNCTION

Figures 3 and 4 show the peak velocities of early and atrial transmitral blood flow after placebo and \pm candoxatrilat. The peak early and atrial filling velocities did not change significantly from baseline after the placebo, and so there was no change in the $E$ :A ratio. After \pm candoxatrilat, however, there was a significant fall in

Effects of \pm candoxatrilat on haemodynamics and haematocrit

\begin{tabular}{|c|c|c|c|c|c|c|c|c|}
\hline \multirow[b]{2}{*}{ Treatment } & \multicolumn{8}{|c|}{ Time after dose (h) } \\
\hline & 0 & 1 & & 2 & & 4 & 8 & \\
\hline $\begin{array}{l}\text { 土 Candoxatrilat: } \\
\text { HR (beats/min) } \\
\text { SBP (mm Hg) } \\
\text { DBP }(\mathrm{mm} \mathrm{Hg}) \\
\text { CO }(1 / \mathrm{min}) \\
\text { SVR }\left(\mathrm{d} / \mathrm{s} / \mathrm{cm}^{-5}\right) \\
\text { PCV }(\%)\end{array}$ & $\begin{aligned} 78 & (7) \\
114 & (5) \\
76 & (4) \\
4.9 & (0 \cdot 4) \\
1328 & (92) \\
40.9 & (1.8)\end{aligned}$ & $\begin{array}{c}80 \\
119 \\
78 \\
5 \cdot 1 \\
1429 \\
42\end{array}$ & $\begin{array}{l}(9) \\
(7) \\
(3) \\
(0 \cdot 4) \\
(119) \\
(2 \cdot 3)\end{array}$ & $\begin{array}{c}82 \\
115 \\
79 \\
4 \cdot 6 \\
1546 \\
41 \cdot 4\end{array}$ & $\begin{array}{l}(8) \\
(6) \\
(3) \\
(0 \cdot 4) \\
(137) \\
(3)\end{array}$ & $\begin{aligned} 79 & (7) \\
115 & (3) \\
78 & (3) \\
4 \cdot 8 & (0 \cdot 4) \\
1446 & (98) \\
40.9 & (1 \cdot 8)\end{aligned}$ & $\begin{array}{c}79 \\
120 \\
79 \\
4 \cdot 8 \\
1482 \\
41 \cdot 2\end{array}$ & $\begin{array}{l}(5) \\
(5) \\
(4) \\
(0 \cdot 4) \\
(83) \\
(1 \cdot 7)\end{array}$ \\
\hline $\begin{array}{l}\text { Placebo: } \\
\text { HR (beats/min) } \\
\text { SBP (mm Hg) } \\
\text { DBP }(\mathbf{m m ~ H g}) \\
\text { CO }(1 / \mathrm{min}) \\
\text { SVR }\left(\mathrm{d} / \mathbf{s} / \mathrm{cm}^{-5}\right) \\
\text { PCV }\end{array}$ & $\begin{array}{cl}80 & (9) \\
116 & (8) \\
76 & (5) \\
5 \cdot 1 & (0 \cdot 6) \\
1328 & (92) \\
40.6 & (1 \cdot 4)\end{array}$ & $\begin{array}{r}78 \\
115 \\
78 \\
5 \\
1429 \\
40 \cdot 4\end{array}$ & $\begin{array}{l}(6) \\
(7) \\
(4) \\
(0 \cdot 4) \\
(119) \\
(1 \cdot 6)\end{array}$ & $\begin{array}{c}78 \\
114 \\
74 \\
4 \cdot 9 \\
1546 \\
40\end{array}$ & $\begin{array}{l}(8) \\
(6) \\
(4) \\
(0 \cdot 5) \\
(137) \\
(1 \cdot 1)\end{array}$ & $\begin{array}{cl}76 & (5) \\
116 & (7) \\
76 & (4) \\
4 \cdot 8 & (0 \cdot 5) \\
1446 & (98) \\
38 \cdot 1 & (1 \cdot 4)\end{array}$ & $\begin{array}{c}79 \\
117 \\
76 \\
5 \\
1482 \\
39 \cdot 7\end{array}$ & $\begin{array}{l}(8) \\
(8) \\
(4) \\
(0 \cdot 4) \\
(83) \\
(1 \cdot 4)\end{array}$ \\
\hline
\end{tabular}

Changes in haemodynamics and packed cell volume after \pm candoxatrilat and placebo are shown as mean (SEM) for six patients. None of the effects was statistically significant.

HR, heart rate; SBP, systolic blood pressure; DBP, diastolic blood pressure; CO, cardiac output; SVR, systemic vascular resistance; PCV, packed cell volume. 
Figure 4 Doppler assessment of left ventricular diastolic function after

+ candoxatrilat: mean (SEM) peak early and atrial filling velocities, and $E: A$ ratio.
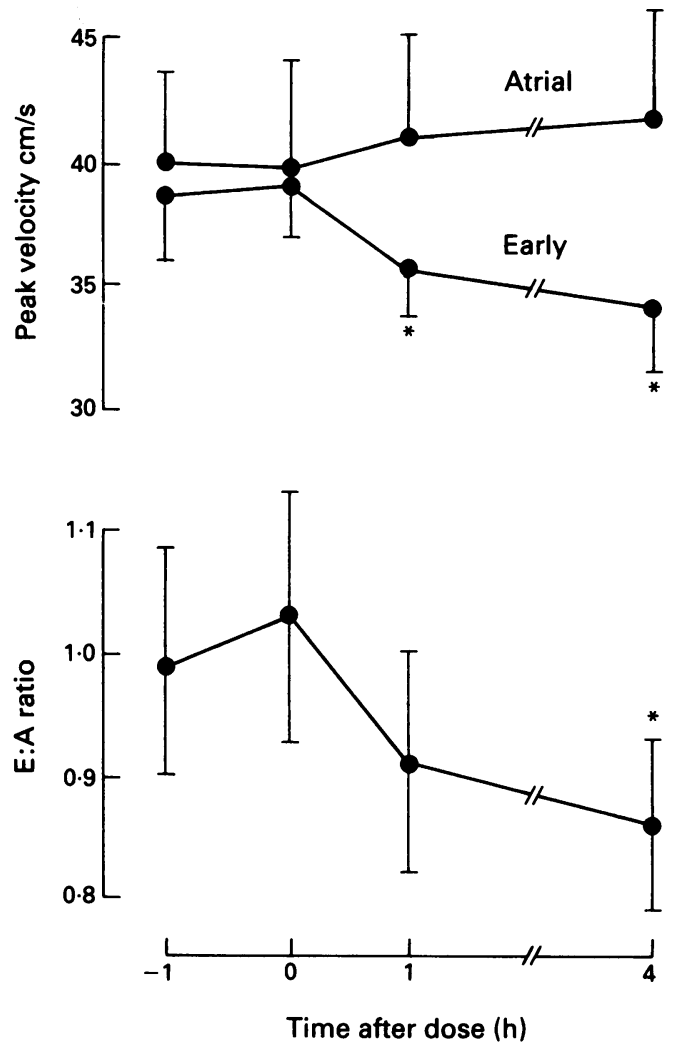

the mean peak early filling velocity from 39.5 $(5 \cdot 1)$ to $34 \cdot 2(6 \cdot 1) \mathrm{cm} / \mathrm{s}(\mathrm{p}<0.05)$, with a rise in peak atrial filling velocity from $39.7(10.3)$ to $41.6(11.2)$ (NS). The E:A ratio, a Doppler index of left ventricular diastolic function, fell from $1.04(0.28)$ to $0.87(0.22)(p<0.05)$. This effect is opposite to the predicted response if the falls in filling pressure had been due to improved early left ventricular relaxation. Thus diastolic function did not improve after \pm candoxatrilat.

\section{Discussion}

The results of this initial, placebo controlled, dose ranging study show that competitive inhibition of neutral endopeptidase by \pm candoxatrilat is associated with rises of plasma ANF in patients with mild heart failure. The haemodynamic changes that were found after \pm candoxatrilat are very similar to those reported for ANF infusions in patients with chronic heart failure..$^{2-5}$ The principal effect was a moderate and prolonged fall in right and left ventricular filling pressures that was still apparent eight hours after dosing, even though the plasma ANF concentration had returned to baseline by this time. A similar prolonged effect has been reported after short-term intravenous infusions of ANF. ${ }^{23}$ This could be explained by a change in effective blood volume, a sustained interaction between ANF and its receptor, potentiation of other natriuretic peptides (for example BNP), or a second messenger with a more prolonged effect on vascular smooth muscle cells (cyclic guanosine monophosphate). ${ }^{14}$

Possible causes of the fall in filling pressures include an improvement in left ventricular systolic or diastolic performance, a fall in plasma volume, an increase in resistance to venous filling, or a rise in venous capacitance. We did not find any evidence of a positive inotropic effect as there was no rise in stroke volume or cardiac output. A significant fall in plasma volume is unlikely since there was no rise in packed cell volume after \pm candoxatrilat. This is, however, a crude method for measuring changes in plasma volume especially when frequent blood sampling for other assays is performed, and it is possible that a small change could have been missed by this technique. Although a fall in plasma volume has been found during ANF infusions in normal volunteers, this has not been reported in patients with chronic heart failure, which lends support to our findings. ${ }^{4}$

A further possible mechanism of the fall in cardiac filling pressures that has received little attention in the past is improved left ventricular diastolic performance, which we assessed non-invasively with Doppler echocardiography. Various conditions that impair left ventricular relaxation, including hypertrophy, ischaemia, and ageing, also reduce the Doppler index E:A ratio. ${ }^{13}$ This index of diastolic function can be affected by nonmyocardial factors, in particular the ventricular loading conditions, which can make interpretation of the E:A ratio in individual patients difficult. Nevertheless it is a useful means of assessing the response to an intervention as long as baseline measurements are available as a control. If the fall in cardiac filling pressures in this study had been due to improved diastolic function, an increase in the E:A ratio would have been expected. In fact the opposite effect was seen. This does not necessarily imply any detrimental effect on diastolic function because the results can be explained by the change in ventricular loading conditions, which would reduce the rate of early diastolic filling. Thus our results do not support a role for an improvement in myocardial systolic or diastolic performance, or a reduction in plasma volume as the cause of the fall in filling pressures produced by \pm candoxatrilat. These findings are in keeping with previous experimental experience of ANF infusions. ${ }^{3-5}$

It therefore seems likely that the rise in ANF after \pm candoxatrilat had an effect on the peripheral vasculature. In one study of rats it was suggested that an increased resistance to venous filling due to venoconstriction was the cause of the fall in right atrial pressure that occurred during ANF infusion. ${ }^{15}$ Studies in man, however, do not support this hypothesis. In vitro experiments on excised large veins in water baths have not shown ANF to have any effect, even in very large doses. ${ }^{16}$ Furthermore an in vivo study found that direct infusion of ANF into a dorsal hand vein had no noticeable effect on venous tone. ${ }^{17}$ The large veins studied in both of these experiments are not the principal determinants of venous capacitance. This is dependent on the tone of small venules present in the peripheral muscles, and so is harder to determine directly. One study of such capacitance venules in rat cremaster muscle, 
which had been preconstricted with noradrenaline, showed significant $(70 \%)$ dilatation with a low concentration of ANF. ${ }^{18}$ Therefore we think that the fall in right and left ventricular filling pressures that we have found after \pm candoxatrilat, and others have seen during infusion of ANF, is due to dilatation of venous capacitance vessels, although we cannot exclude the possibility of a small fall in effective blood volume.

This study has some limitations. The small number of patients studied leads to a risk of type II error, although the cross over design compensates to some extent. The patients received increasing doses of \pm candoxatrilat because we wished to establish the safety of each dose before progressing to a higher dose. This was unavoidable as it was the first study of an endopeptidase inhibitor in patients with heart failure. Consequently only two patients received each dose, so it was necessary to pool the data from different doses to make statistical comparisons possible. We have already discussed the limitations of the Doppler measurement of diastolic function used in this study.

In conclusion, we have shown that inhibition of neutral endopeptidase by \pm candoxatrilat leads to a threefold rise in concentration of plasma ANF in mild heart failure. The principal acute haemodynamic effect is a fall in cardiac filling pressures. This was not due to an improvement in left ventricular systolic or diastolic performance, but suggests a peripheral vascular effect.

DBN was a British Heart Foundation junior research fellow. This study was supported by a grant from Pfizer Central Research, Sandwich, Kent.

1 de Bold AJ, Borenstein HB, Veress AT, Sonnenberg H. A rapid and potent natriuretic response to intravenous injection of atrial myocardial extracts in rats. Life Sci 1981;28:89-94.
2 Crozier IG, Nicholls MG, Ikram H, Espiner EA, Gomez HJ, Warner NJ. Haemodynamic effects of atrial peptide infusion in heart failure. Lancet 1986;ii:1242-5.

3 Molina CR, Fowler MB, McCrory S, Peterson C, Myers BD, Schroeder JS, Murad F. Hemodynamic, renal and endocrine effects of atrial natriuretic peptide infusion in endocrine effects of atrial natriuretic peptide infusion in

4 Cody RJ, Atlas SA, Laragh JH, Kubo SH, Covit AB, Ryman $\mathrm{KS}$, et al. Atrial natriuretic factor in normal subjects and KS, et al. Atrial natriuretic factor in normal subjects

5 Herrmann HC, Palacios IF, Dec GW, Scheer JM, Fifer MA. Effects of atrial natriuretic factor on coronary hemodynamics and myocardial energetics in patients with hear failure. Am Heart J 1988;115:1232-8.

6 Stephenson SL, Kenny AJ. The hydrolysis of human atria natriuretic peptide by pig kidney microvillar membranes is initiated by endopeptidase-24:11. Biochem J 1987; 243:183-7.

7 Sonnenberg JL, Sakane Y, Jeng AY, Koehn JA, Ansell JA, Wennogle LP, Ghai RD. Identification of proteas 3.4.24.11 as the atrial natriuretic factor degrading enzyme in the rat kidney. Peptides 1987;9:173-80.

8- Danilewitz JC, Barclay PL, Barnish IT, Brown D, Campbel $\mathrm{SF}$, James $\mathrm{K}$, et al. \pm Candoxatrilat, a novel inhibitor of EC 3.4.24.11 which increases endogenous ANF levels and is natriuretic and diuretic. Biochem Biophys Res Commun 1989;164:58-64.

9 Jardine AG, Connell JMC, Northridge DB, Dilly SG, Cussans NJ, Davidson G, et al. The atriopeptidase inhibitor \pm candoxatrilat increases atrial natriuretic facto and causes a natriuresis in normal humans. Am J Hyperten 1990;3:661-7.

10 Northridge DB, Jardine AG, Findlay IM, Archibald M, Dilly SG, Dargie HJ. Inhibition of the metabolism of atrial natriuretic factor causes natriursis and diuresis in chronic heart failure. Am J Hypertens 1990;3:682-7.

11 Richards AM, Tonolo G, McIntyre GD, Leckie BJ, Dargie HJ, Ball SG, Robertson JIS. Radio-immunoassay for plasma alpha human atrial natriuretic peptide: comparison plasma alpha human atrial natriuretic peptide: comparison
of direct and pre-extracted methods. J Hypertens 1987; 5:227-36.

12 Friedman BJ, Plehn JF. Non-invasive analysis of ventricular diastolic performance: in quest of a clinical tool. $\mathrm{J} \mathrm{Am} \mathrm{Coll}$ Cardiol 1988;12:944-6.

13 Spirito P, Maron BJ. Influence of ageing on Doppler echocardiographic indices of left ventricular diastolic function. Br Heart $J$ 1988;59:672-9.

14 Murad F. Cyclic guanosine monophosphate as a mediator of vasodilatation. J Clin Invest 1986;78:1-5.

15 Chien YW, Frohlich ED, Trippodo NC. Atrial natriuretic peptide increases resistance to venous return in rats. $\mathrm{Am}$ Physiol 1987;252:894-9.

16 Hughes A, Thom S, Goldberg P, Martin G, Sever P. Direct effect of atrial natriuretic peptide on human vasculature in vivo and in vitro. Clin Sci 1988;74:207-11.

17 Webb DJ, Benjamin N, Allen MJ, Brown J, O'Flynn M, Cockcroft JR. Vascular responses to local atrial natriuretic peptide infusion in man. Br J Clin Pharmacol 1988;25: peptide inf $245-51$.

18 Faber JE, Gettes DR, Gianturco DP. Microvascular effects of atrial natriuretic factor: Interaction with alpha adrenoreceptors. Circ 1988;63:415-28. 